\title{
T2 Fluid-Attenuated Inversion Recovery Imaging of Uveal Melanomas and Other Ocular Pathology
}

\author{
Gena M. Damento $^{a}$ Kelly K. Koeller ${ }^{b}$ Diva R. Salomão ${ }^{c}$ Jose S. Pulido ${ }^{a} d$ \\ Departments of ${ }^{\mathrm{a}}$ Ophthalmology, ${ }^{\mathrm{b}}$ Radiology, ${ }^{\mathrm{c}}$ Anatomic Pathology and ${ }^{\mathrm{d}}$ Molecular Medicine, Mayo Clinic, \\ Rochester, Minn., USA
}

\section{Key Words}

Choroidal hemangioma - Melanoma $\cdot$ Magnetic resonance imaging · Posttreatment changes $\cdot$ T2 fluid-attenuated inversion recovery . Uveal melanoma

\begin{abstract}
Background/Aims: This study describes patterns of intraocular lesions on T2 fluid-attenuated inversion recovery (FLAIR) imaging, exploring a prospective role of FLAIR imaging sequence in diagnosis and treatment. Methods: A retrospective study of orbital magnetic resonance imaging (MRI) studies from the years 2000 to 2015 was performed. MRI sequences included: pre-contrast T1-weighted, T2-weighted, T2 FLAIR, and postcontrast $\mathrm{T} 1$ and $\mathrm{T} 2$ imaging gadolinium, which were evaluated by a neuroradiologist. Two cases of melanoma were correlated to their pathology. Results: Twenty-four patients with intraocular pathology were evaluated. All lesions, regardless of pigmentation, revealed previously described melanotic patterns on T1- and T2-weighted images; $80 \%$ of 10 melanomas localized were hyperintense on T2 FLAIR, which better delineated lesion margins. All of the four inflammatory pathologies on T2 FLAIR were hyperintense, as were $80 \%$ of the amelanotic neoplasms. Pathology of two large uveal melanomas paralleled the findings seen on T2 FLAIR. Conclusions: T2 FLAIR appears beneficial
\end{abstract}

in the demarcation of pigmented ocular lesions and may aid in determining protein content or previous treatment. Data also promote previous assertions that blood flow impacts intensity of lesions on T2 FLAIR. Further research is warranted.

(c) 2016 S. Karger AG, Basel

\section{Introduction}

Multiple imaging techniques are currently employed to visualize and guide treatment of uveal melanomas, the most common being ultrasonography and magnetic resonance imaging (MRI) [1-5]. Early studies utilizing ultrasonography in the evaluation of uveal melanomas highlighted the benefits from measurement of tumor thickness and the impact on therapy [6].

MRI findings are beneficial in determining the extent of ocular tumors and involvement of orbital and extraorbital structures $[7,8]$. This is specifically valuable when determining the treatment or prognostication of patients with concern for malignancy. A higher risk of tumor growth after treatment has been correlated with greater

Presented as an oral presentation in June 2015 at the International Society of Ocular Oncology in Paris, France.

\section{KARGER}

E-Mail karger@karger.com www.karger.com/oop (c) 2016 S. Karger AG, Basel

2296-4681/16/0024-0251\$39.50/0
Jose S. Pulido, MD, MBA, MPH, MS

Mayo Clinic

Department of Ophthalmology and Department of Molecular Medicine

200 First Street, SW, Rochester, MN 55905 (USA)

E-Mail pulido.jose@mayo.edu 


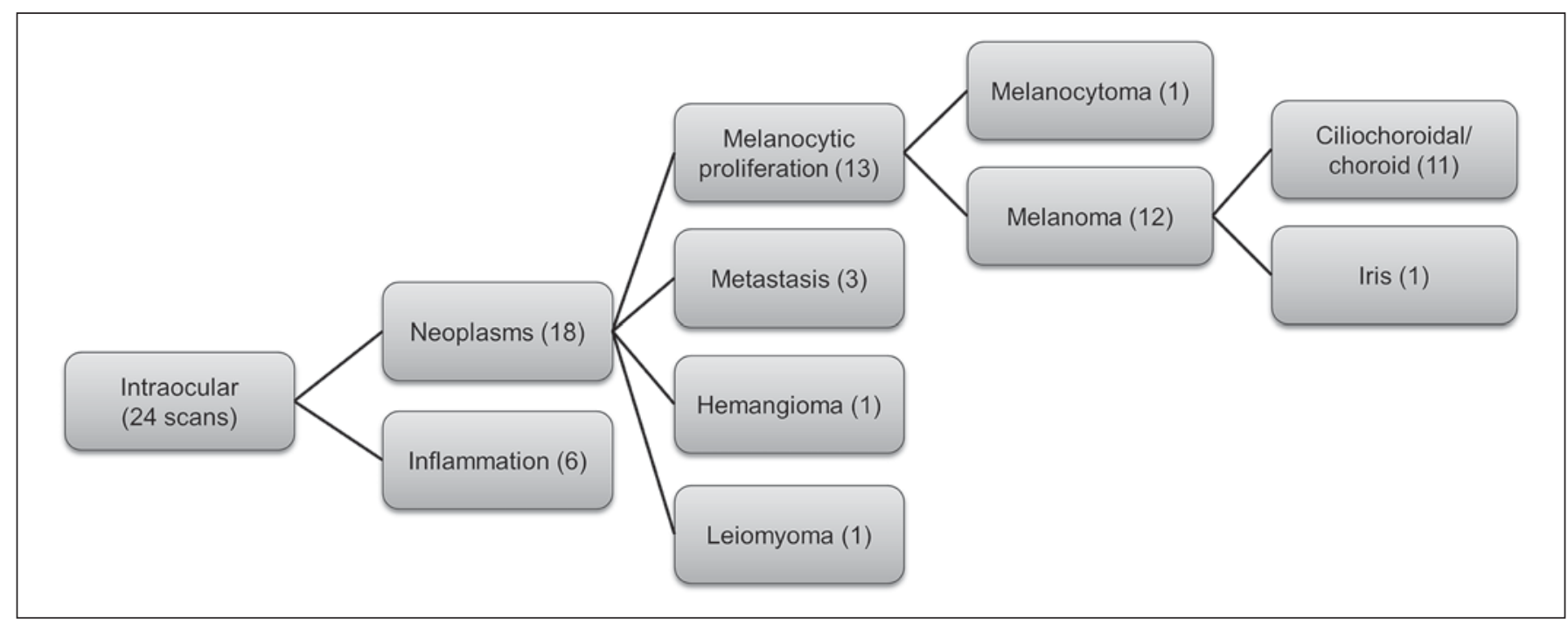

Fig. 1. Schematic showing the breakdown of MRI scans analyzed.

volumes [9]; the ability to determine a lesion's size is, thus, an important tool when identifying options. In lesions followed with serial MRIs, a change in size may indicate more invasive treatments including enucleation, further emphasizing the need for accurate delineation of borders. MRI is also currently used to spatially determine a lesion's parameters for gamma knife treatment.

Characterizing lesions on MRI has been more widely researched in the context of brain pathology than the orbit [10-17]. Routine MRI of the brain and orbit typically includes T1-weighted and T2-weighted sequences without and with intravenous contrast administration in axial, coronal, or sagittal planes to allow a full characterization of changes in signal intensity within tissues of interest.

T2 fluid-attenuated inversion recovery (FLAIR) is a type of MRI sequence that employs an inversion pulse followed by a long inversion time that produces significant decrease in fluid signal intensity. On images from this sequence, the cerebrospinal fluid is quite hypointense and makes areas of altered signal intensity within the adjacent brain - particularly along the margins of the ventricles and sulcal margins - much more conspicuous in most circumstances [18-21].

More recent studies have also demonstrated that hyperintense vessels on FLAIR sequences may be seen in regions of acute cerebral infarction and are regarded to represent slow blood flow through collateral arterial vasculature, either from occlusion, vasospasm, or stenosis
[22-24]. Signal changes from the blood clot itself, perhaps reflecting an effect of oxyhemoglobin, may also contribute to this imaging manifestation [24]. One study addressing basilar artery occlusion showed that the length of FLAIR hyperintensity within the vessel directly correlated with poorer prognosis [24]. Hyperintensity of hepatic hemangiomas on FLAIR sequences has also been used to distinguish these lesions from cysts and also presumably reflecting slow flow within these vascular collections [25]. Finally, one study proposes that melanin is hyperintense on FLAIR, though this has only been shown in vegetative tissue [26]. To our knowledge, there is no information in the literature regarding the pattern of uveal melanomas on T2 FLAIR sequences. T2 FLAIR imaging could provide another method to distinguish melanomas from other intraocular mass-forming lesions and may better delineate the neoplasm. If proven to have these characteristics, T2 FLAIR imaging should be added to current orbital scan sequences as it would contribute to the treatment and prognostication of patients with suspected melanotic lesions.

\section{Materials, Subjects, and Methods}

MRI scans of 24 patients with intraocular lesions were analyzed and organized according to location and type of pathology (fig. 1). Scans were performed on either General Electric scanners at strengths of 1.5 or 3.0 Tesla (manufactured in Milwaukee, Wis., USA) or on Siemens scanners at 3.0 Tesla (manufactured in Erlan- 
Table 1. Data of intraocular tumors, lesions, and inflammatory pathologies

\begin{tabular}{|c|c|c|c|c|c|c|}
\hline Scan & Lesion type & $\begin{array}{l}\text { Hyper } \\
(\%)\end{array}$ & $\begin{array}{l}\text { Iso } \\
(\%)\end{array}$ & $\begin{array}{l}\text { Hypo } \\
(\%)\end{array}$ & $\begin{array}{l}\text { Total, } \\
\mathrm{n}\end{array}$ & Comments \\
\hline \multirow[t]{3}{*}{ T1WI } & Melanoma & $13(100)$ & $0(0)$ & $0(0)$ & 13 & \\
\hline & Nonpigmented neoplasms & $4(100)$ & $0(0)$ & $0(0)$ & 4 & 1 not localized \\
\hline & Inflammatory & $4(100)$ & $0(0)$ & $0(0)$ & 4 & $\begin{array}{l}1 \text { no focal lesion, } \\
1 \text { not performed }\end{array}$ \\
\hline \multirow[t]{3}{*}{ T2WI } & Melanoma & $0(0)$ & $0(0)$ & $12(100)$ & 12 & 1 not localized \\
\hline & Nonpigmented neoplasms & $0(0)$ & $0(0)$ & $3(100)$ & 3 & 2 not performed \\
\hline & Inflammatory & $0(0)$ & $0(0)$ & $4(100)$ & 4 & $\begin{array}{l}1 \text { no focal lesion, } \\
1 \text { not performed }\end{array}$ \\
\hline \multirow[t]{3}{*}{ T2 FLAIR } & Melanoma & $8(80)$ & $1(10)$ & $1(10)$ & 10 & $\begin{array}{l}2 \text { not localized, } \\
1 \text { not performed }\end{array}$ \\
\hline & Nonpigmented Neoplasms & $4(80)$ & $1(20)$ & $0(0)$ & 5 & \\
\hline & Inflammatory & $4(100)$ & $0(0)$ & $0(0)$ & 4 & $\begin{array}{l}1 \text { no focal lesion, } \\
1 \text { not performed }\end{array}$ \\
\hline \multirow[t]{3}{*}{ Gad T1 } & Melanoma & $12(100)$ & $0(0)$ & $0(0)$ & 12 & 1 not localized \\
\hline & Nonpigmented neoplasms & $5(100)$ & $0(0)$ & $0(0)$ & 5 & \\
\hline & Inflammatory & $2(100)$ & $0(0)$ & $0(0)$ & 2 & $\begin{array}{l}1 \text { no focal lesion, } \\
3 \text { not performed }\end{array}$ \\
\hline \multirow[t]{3}{*}{ Gad T2 } & Melanoma & $0(0)$ & $0(0)$ & $5(100)$ & 5 & 8 not performed \\
\hline & Nonpigmented neoplasms & $0(0)$ & $0(0)$ & $1(100)$ & 1 & $\begin{array}{l}2 \text { not localized, } \\
2 \text { not performed }\end{array}$ \\
\hline & Inflammatory & $0(0)$ & $0(0)$ & $1(100)$ & 1 & $\begin{array}{l}1 \text { no focal lesion, } \\
4 \text { not performed }\end{array}$ \\
\hline
\end{tabular}

Number of pigmented lesions noted as hyperintense (Hyper), isointense (Iso), and hypointense (Hypo) in comparison to the vitreous humor. Gad $=$ Gadolinium.

gen, Germany). For each patient, the signal intensity of the lesion in question was compared to the vitreous humor and was accordingly recorded as hyperintense, isointense, or hypointense. Analyzed sequences included T1-weighted imaging (T1WI), T2weighted imaging (T2WI), T2 FLAIR imaging, and postcontrast T1WI and T2WI. Only axial scans were used for standardization, and content was confirmed by a board-certified neuroradiologist.

Other patients were included in this study as individual cases whose scans were performed after the initial group was determined. Their individual findings on T2 FLAIR are discussed in the 'Additional Findings' section below.

\section{Results}

\section{Intraocular Pigmented Tumors}

Of the 24 patients, 12 (50\%) had the diagnosis of uveal melanoma and one had a histologically confirmed melanocytoma. In parallel to previous studies, all 13 were found to be hyperintense on T1WI and hypointense on T2WI when compared to the vitreous humor (table 1).
Of the 13,1 patient did not have a T2 FLAIR scan available, and 2 patients did not have localizable lesions. Eighty percent of the remaining 10 pigmented lesions were found to be hyperintense on T2 FLAIR in comparison to the vitreous humor. Qualitatively, the conspicuity of the pigmented lesions was increased on T2 FLAIR in comparison to that on T1WI (fig. 2a, b). Both of the lesions not localized and one of the hyperintense lesions had received previous radiation treatment.

\section{Nonpigmented Lesions}

The other intraocular lesions included five neoplasms without pigment and six with pathology of inflammatory origin (table 1). All lesions in these groups were also found to be hyperintense on T1WI and hypointense on T2WI when compared to the vitreous humor.

Of the five nonpigmented neoplasms, $80 \%$ were hyperintense on T2 FLAIR in comparison to the vitreous humor; $20 \%$ appeared isointense, leaving no lesions hy- 
Fig. 2. Uveal melanoma. Example of T1weighted image (a) compared to T2 FLAIR image (b), with more conspicuous hyperintensity on the latter image.
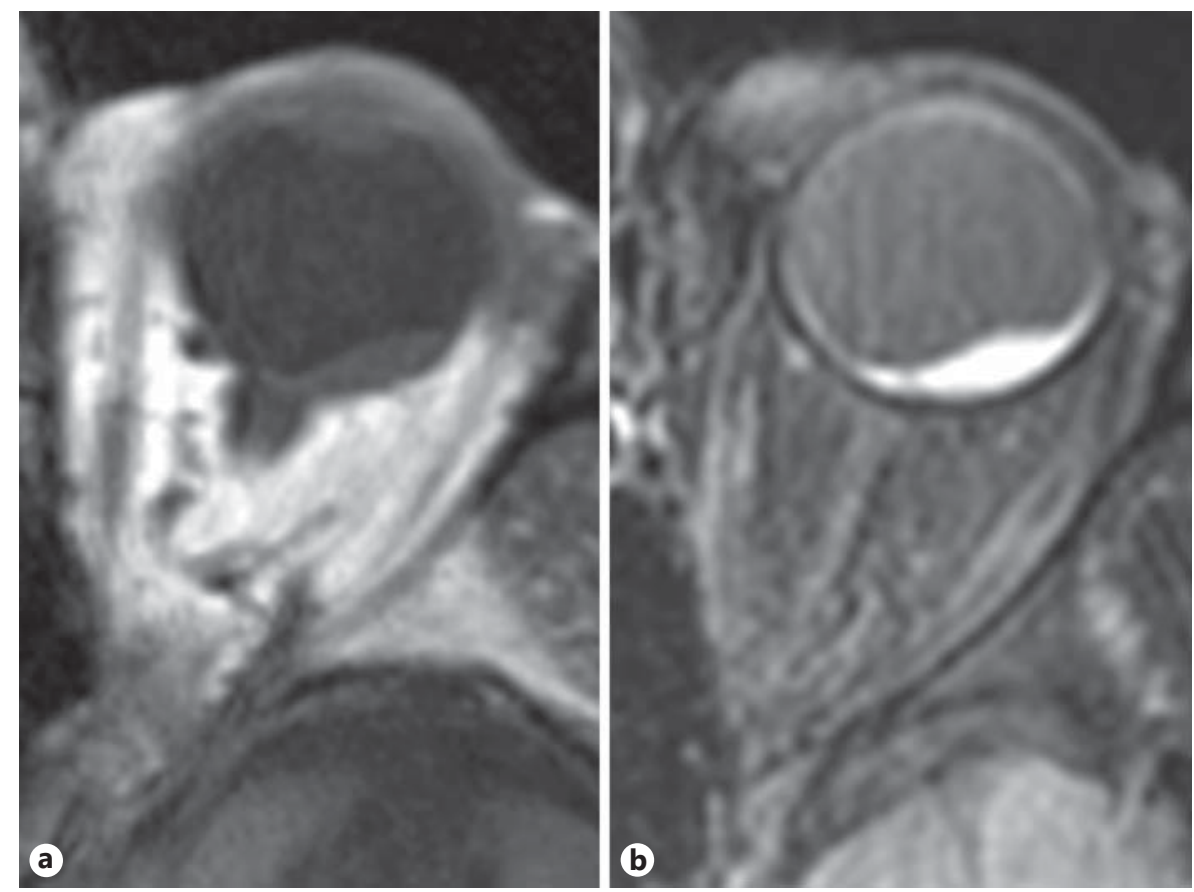

pointense (table 1). Of the six inflammatory pathologies, one was not imaged and one was not a focal lesion. The remaining four were hyperintense to the vitreous humor (table 1).

The single choroidal hemangioma represented in this study was not well identified on either T1WI or on T2WI, which may be, in part, due to its size at $1.6 \mathrm{~mm}$ thickness by ultrasonography. The lesion was slightly hyperintense and hypointense to the vitreous humor on T1WI and T2WI, respectively. The hemangioma was more pronounced and hyperintense on T2 FLAIR (fig. 3a, b). High resolution T2WI also allowed for visualization of vessels penetrating the sclera (fig. 3c).

\section{Notable Cases of Increased FLAIR Signal}

Instances of increased signal intensity on T2 FLAIR apart from melanomas were discovered. One of these was a case of idiopathic scleritis presenting with a choroidal effusion. Unlike melanomas, this effusion was difficult to distinguish on T1WI, only appearing slightly more hyperintense than the vitreous humor (fig. 4).

Five of the patients in the study were also found to have increased vitreous signal unilaterally on T2 FLAIR. This asymmetry was either not appreciated or less conspicuous on T1WI taken during the same visit (fig. 5a-e). Corresponding diagnoses or exposures of the impacted eye are listed in table 2.

\section{Additional Findings}

\section{Uveal Melanoma}

One case of uveal melanoma had unexpected findings on T2 FLAIR imaging. The center of the lesion was isointense to physiologic vitreous humor seen in the opposite eye, and the remaining intraocular space was hyperintense (fig. 6a). The same melanoma appeared as expected on T1WI (hyperintense) and T2WI (hypointense) in scans performed at the same visit. Figure $6 \mathrm{~b}$ is another known uveal melanoma with anticipated findings on MRI added for comparison.

The lesion with atypical MRI findings had large areas of necrosis and blood seen on both gross and histological examination, and these areas corresponded with the hypointense areas on T2 FLAIR imaging (fig. $6 \mathrm{c}, \mathrm{d}$ ). The intraocular mass consisted mostly of melanophages, which was confirmed by immunohistochemistry; the cells were Melan A negative and CD68 positive. In contrast, the melanoma with more conventional MRI manifestations (fig. 6b) was found to have viable tumor cells throughout (fig. 6e, f).

\section{Choroidal Hemangioma}

MRI of a choroidal hemangioma, not included in the original study, was later viewed for comparison. The lesion was hyperintense on T2 FLAIR and much easier to localize than on T1WI or T2WI. On T1WI, the lesion was 

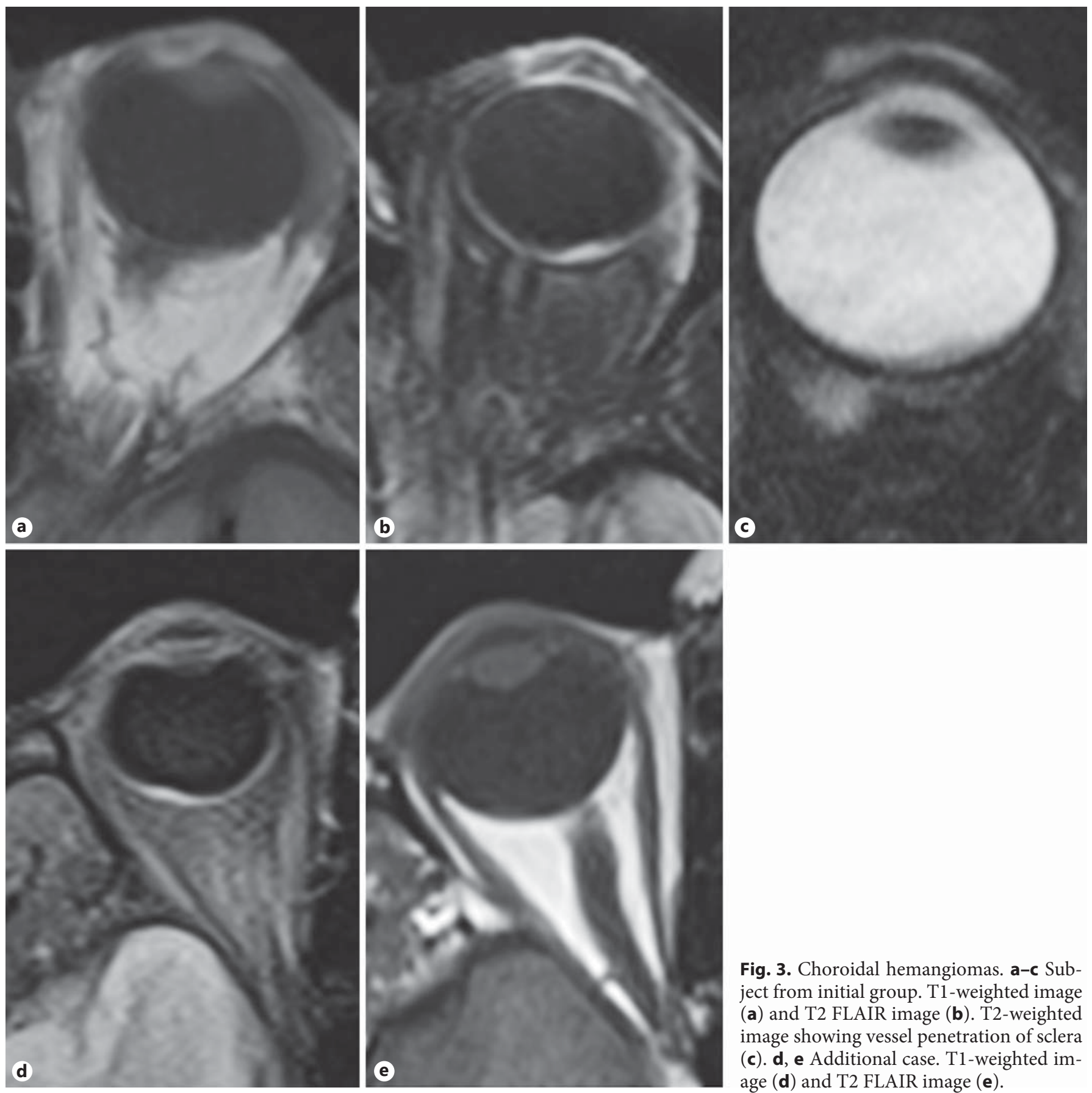

Fig. 3. Choroidal hemangiomas. a-c Subject from initial group. T1-weighted image (a) and T2 FLAIR image (b). T2-weighted image showing vessel penetration of sclera (c). d, e Additional case. T1-weighted image (d) and T2 FLAIR image (e).

isointense to the vitreous humor and was difficult to visualize; however, on T2WI, the choroidal hemangioma was slightly hyperintense to the vitreous humor, yet was less conspicuous when compared to T2 FLAIR (fig. 3c, d).

\section{Posttreatment Changes}

T2 FLAIR images of two patients with melanomas were compared at 11 and 9 months after completion of radiation treatment. Figure 7 reveals the decreased signal intensity seen in both patients. 
Fig. 4. Choroidal effusion. T1-weighted image (a) and T2 FLAIR image (b).
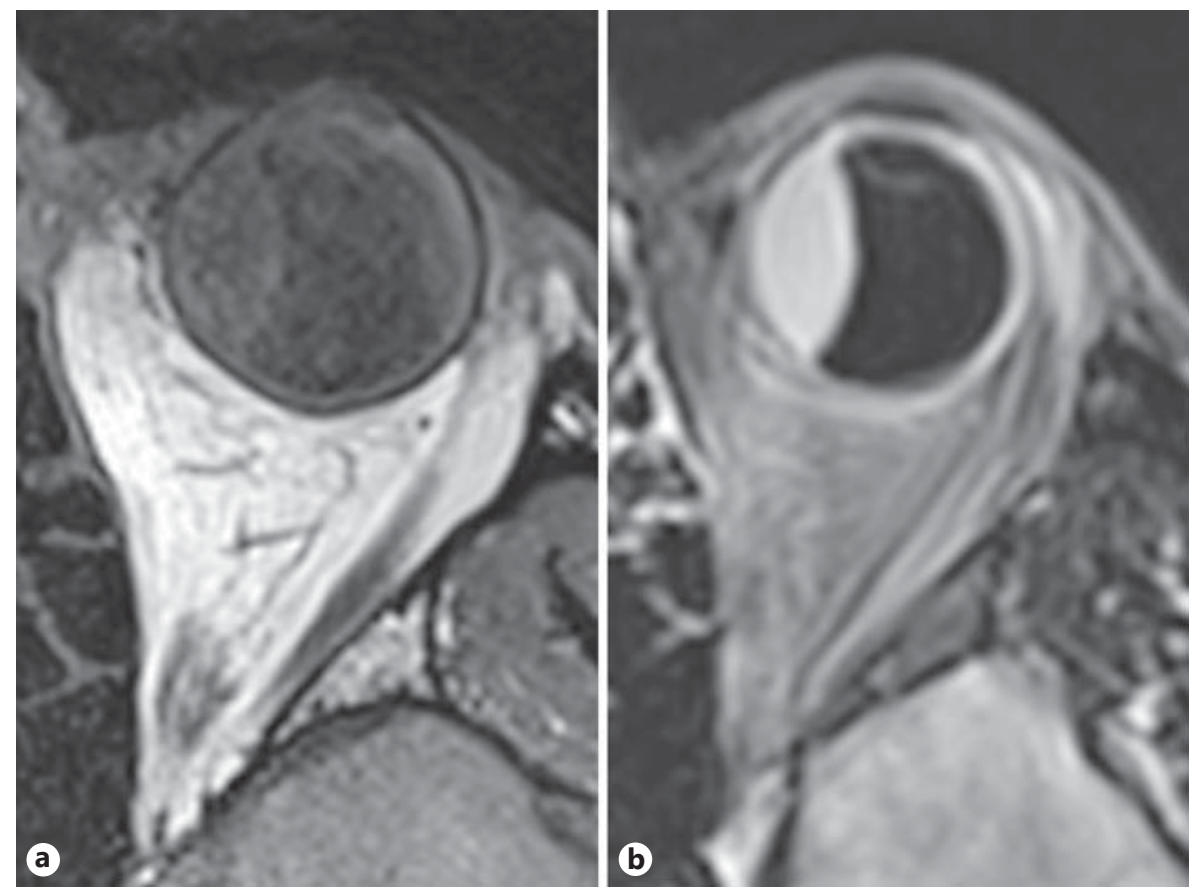

Table 2. Asymmetry on T2 FLAIR: descriptions of intensity differences recorded for the ocular pathologies or exposures

\begin{tabular}{ll}
\hline Ocular pathology/exposure & Density difference \\
\hline OS silicone oil and previous detachment & $\begin{array}{l}\text { OS hyperintense compared to OD, fluid behind } \\
\text { detachment hypodense to silicone oil and vitreous }\end{array}$ \\
\hline $\begin{array}{l}\text { OD retinal hemorrhage, } \\
\text { OS evidence of neovascularization }\end{array}$ & OD slightly more dense than OS \\
\hline $\begin{array}{l}\text { OD complete choroidal detachment, } \\
\text { OS partial choroidal detachment }\end{array}$ & $\begin{array}{l}\text { OD, entire orbit hyperintense } \\
\text { OS, posterior half of orbit hyperintense }\end{array}$ \\
\hline OD chronic inflammation with retinal detachment & OD hyperintense, irregular shaped \\
\hline OD recent vitreous hemorrhage, status post plaque & OS slightly hyperintense \\
\hline \multicolumn{1}{c}{ OS = Left eye; OD = right eye. } & \\
\hline
\end{tabular}

\section{Discussion}

\section{Accuracy of T2 FLAIR for Pigmented Lesions}

The classic MRI appearance of melanoma is hyperintensity on T1WI and hypointensity on T2WI $[1,10]$. This correlation was further endorsed by Gomori et al. [4] who observed similar signal intensity associated with choroidal melanomas, often with a 'mushroom-like' morphology [8].
However, in the diagnosis and treatment of patients with uveal melanomas, researchers conclude that many imaging modalities, including MRI, have yet to take on a specific role $[3,7]$. At this point in time, the literature suggests that the use of MRI in ocular lesions best serves as a compliment to ultrasonography and ophthalmologic examination [27]. This may be the result of a lack in accuracy with diagnosing uveal melanomas solely by MRI. 

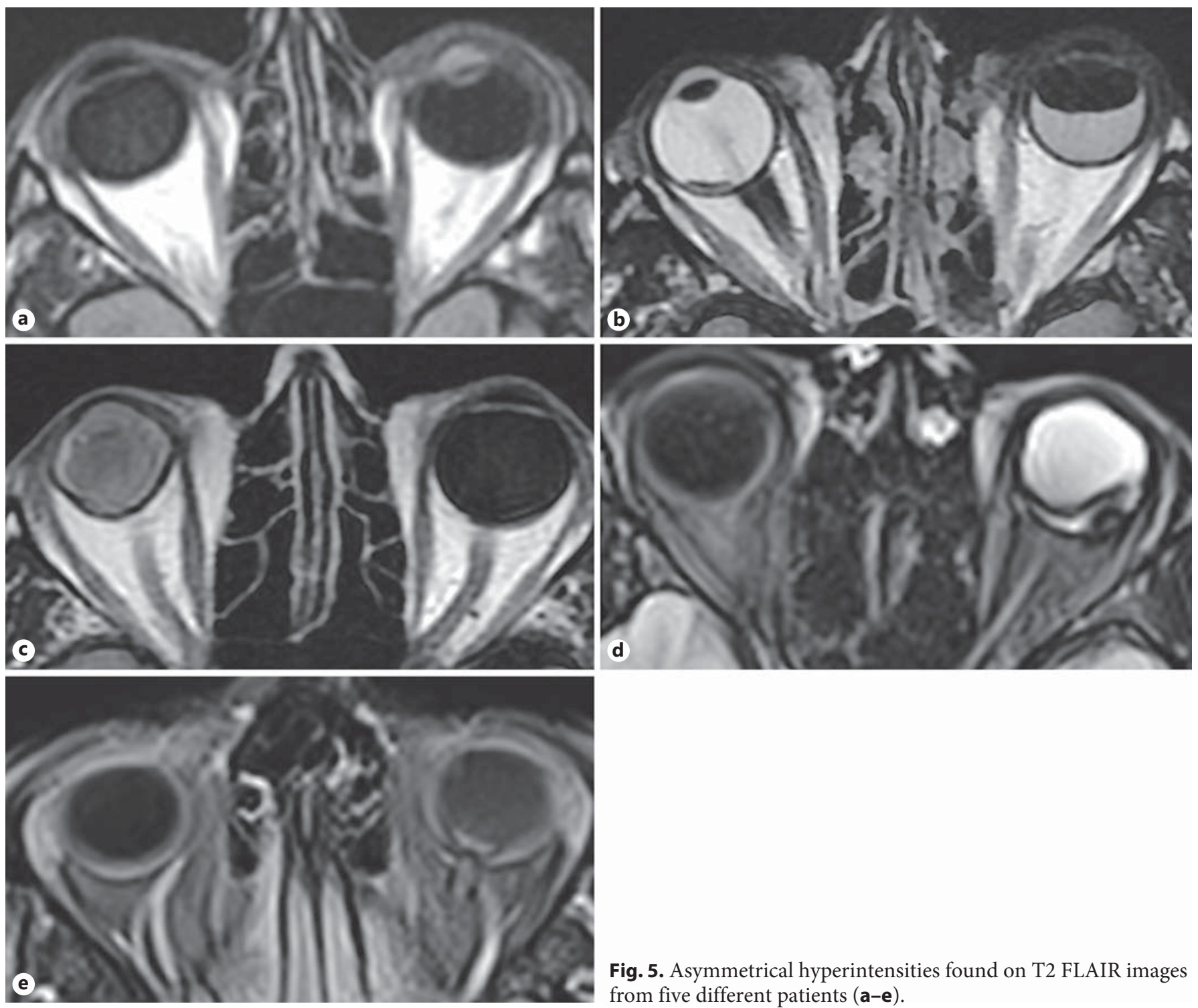

Fig. 5. Asymmetrical hyperintensities found on T2 FLAIR images from five different patients (a-e).

Our findings add another element to the diagnostic potential of MRI in uveal melanomas. Looking at T2 FLAIR sequences, we have shown hyperintensity of these lesions with accuracy similar to that of T1 hyperintensity reported in the literature.

\section{Specificity Concerns of T1WI and T2WI}

In this study, all nonpigmented pathologies, including inflammatory and neoplastic, presented with the same pattern as melanomas, hyperintense on T1WI and hypointense on T2WI, when compared to the vitreous humor. This further suggests that this pattern is nonspecific and emphasizes that it should not be used as a diagnostic measure.

Other causes of a high signal on T1WI can be traced to protein-rich substances [16]. This was also reported by Mafee et al. [5] in patients with vitreitis on both T1WI and T2WI as well as those with a disruption of the blood-retinal barrier.

\section{Increased Conspicuity of Lesions}

As noted above, a benefit of FLAIR imaging is increased conspicuity of uveal melanomas, allowing for better identification of lesions compared to standard T1WI. 

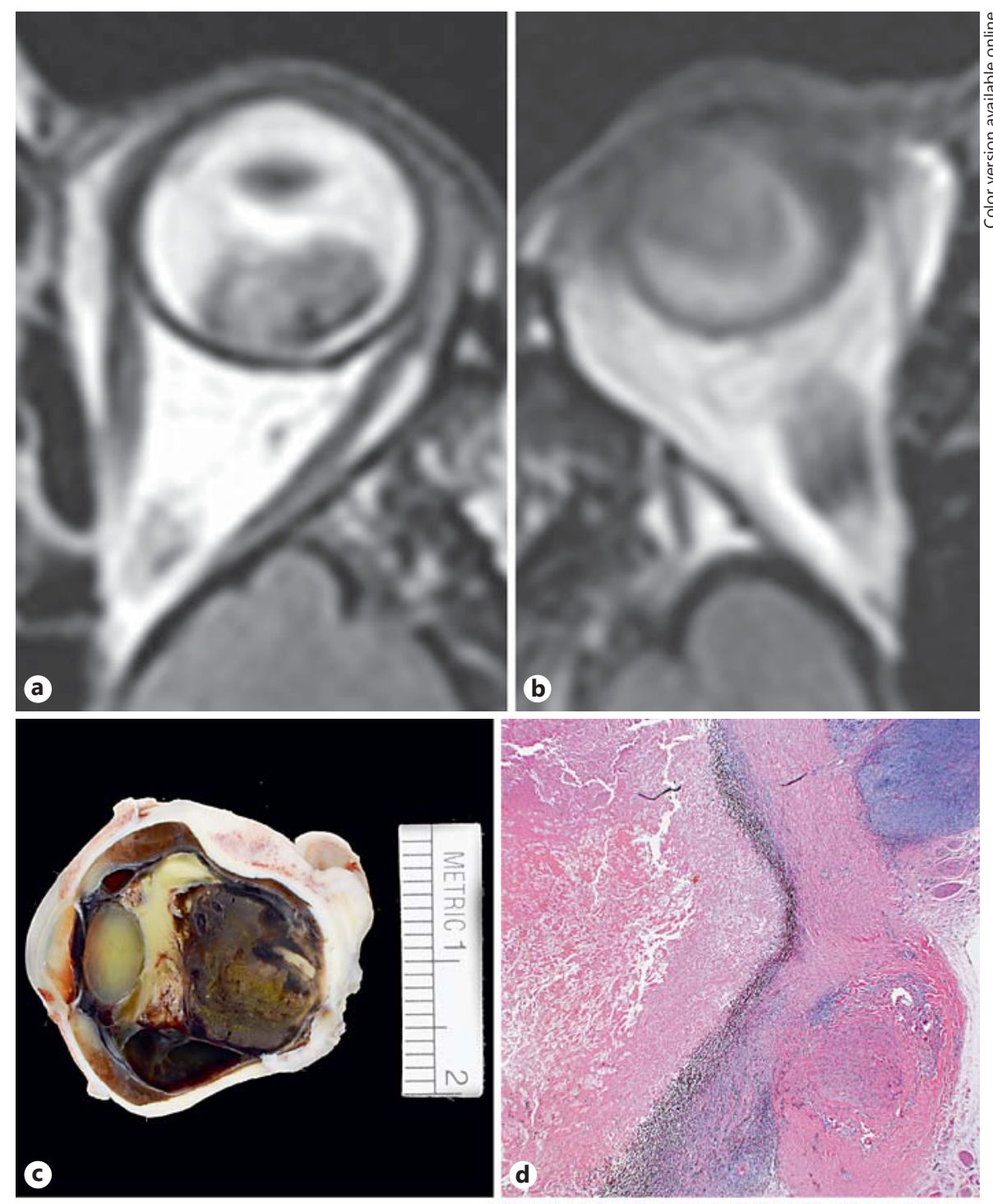

Fig. 6. Uveal melanoma seen on T2 FLAIR image (a), with corresponding gross (c) and histological (d) findings. Another uveal melanoma with T2 FLAIR, gross, and histology (b, e, and f, respectively) shown for comparison.
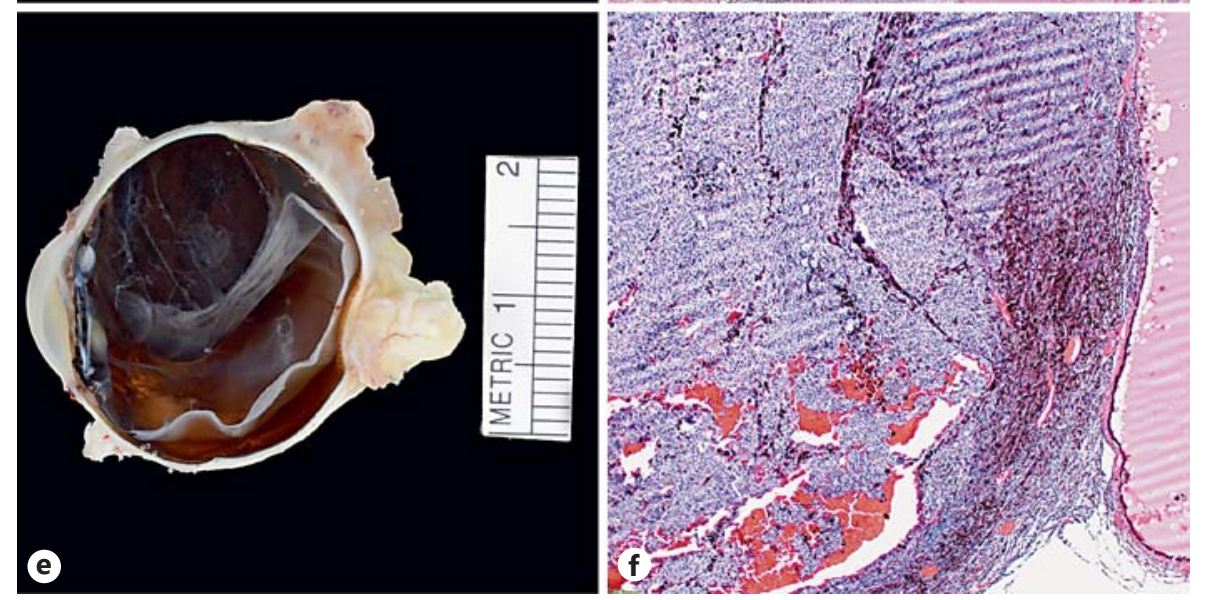

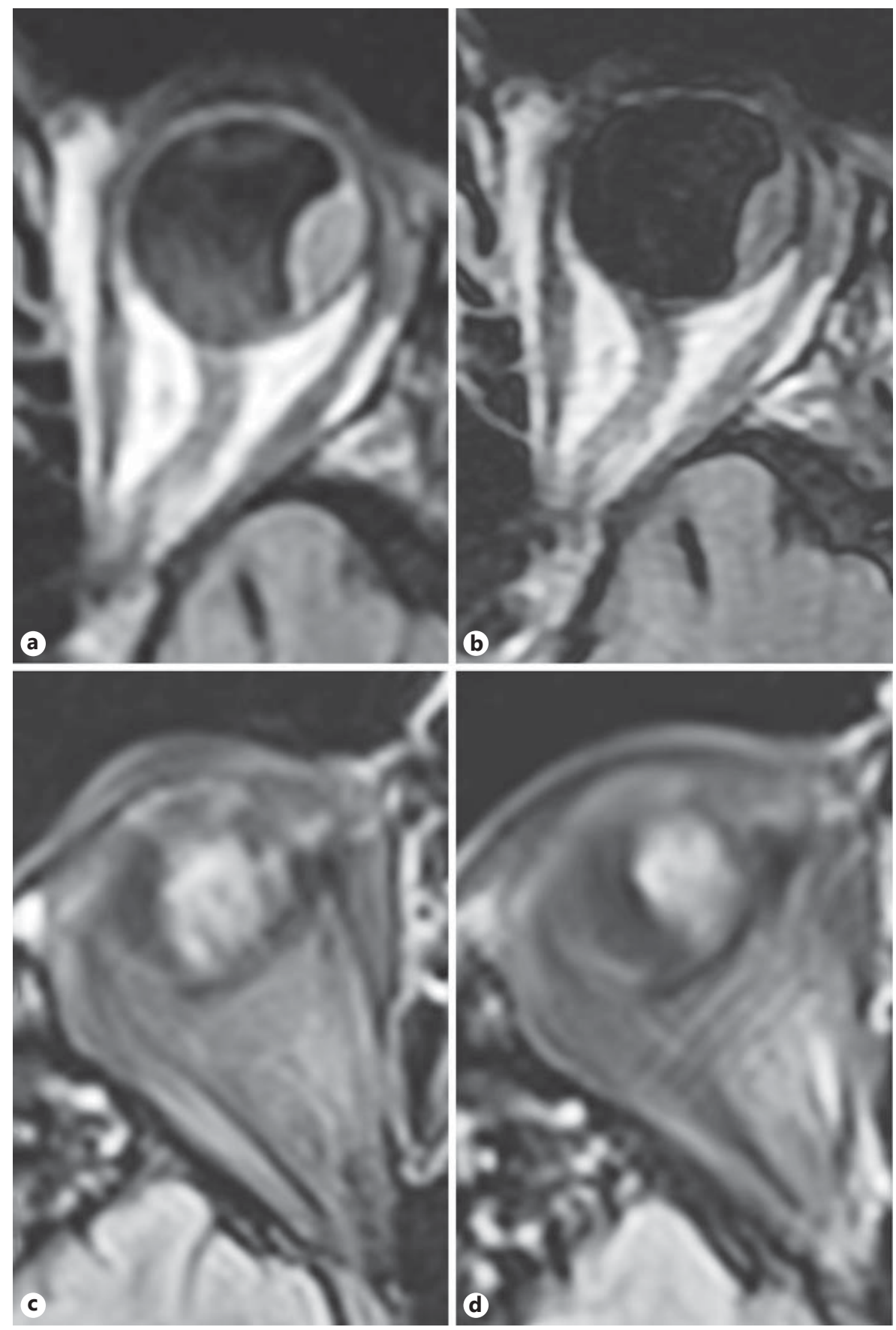

Fig. 7. Posttreatment changes. T2 FLAIR images of a melanoma prior to (a) and 11 months after radiation therapy (b). A second case of melanoma on T2 FLAIR prior to (c) and 9 months after radiation therapy (d).

\section{Significance of Increased Signal on T2 FLAIR}

As an unexpected finding, the uveal melanoma in figure 6 a provides evidence towards determining causality of hyperintense lesions on T2 FLAIR. In distinction to the viable melanoma, the inside of the necrotic tumor was heterogeneously hypointense. Histopathology contributed further insight into the contents of the intraocular 
space, where stagnant blood and melanophages were located. This provides an important example where a melanin-containing area corresponds to T2 FLAIR hypointensity, perhaps reflecting effects of the necrosis and stagnant blood.

This concept is further supported by the two patients whose lesions decreased in intensity on T2 FLAIR after radiation treatment (fig. 7). This is suspected to reflect necrosis and cessation of blood flow posttherapy without change in the melanin content. The decrease in intensity seen here differs from previous data in patients after radiation, where brain lesions have been found to enlarge secondary to inflammation and necrosis [30]. Possible reasons for this include a difference between brain and orbital tissues, different radiation techniques, and the previous failure to comment on T2 FLAIR imaging. As local recurrence has been shown to increase mortality in patients with melanomas, it is critical to correctly identify tissues after treatment [31].

The choroidal effusion secondary to scleritis presents an example of a hyperintense lesion on T2 FLAIR unassociated with melanin content. Although hyperintense on T2 FLAIR, the choroidal effusion was not hyperintense on T1WI as would be expected with a melanoma. This suggests that the signal effect on T2 FLAIR has a separate causality than that of T1WI, which also remains under debate. One explanation is the flow of blood from surrounding vessels, causing this increased signal and emphasizing T2 FLAIR as a measure of slow blood flow. This may contribute to the diagnostic process, aiding in distinguishing pathologies such as choroidal effusions from melanomas.

It may also suggest that T2 FLAIR is more sensitive to proteinaceous or hemorrhagic content. This is further suggested by the five patients with asymmetric signal intensity of the vitreous humor on T2 FLAIR in patients with unilateral lesions. In one patient, silicone oil added to the vitreous humor was the suspected cause. One patient presented with a complete choroidal detachment, while two of the patients had a recent history of vitreous hemorrhage, suggesting blood or blood byproducts may have produced the hyperintensity. The final patient was noted to have increased signal intensity in the eye, which had ongoing chronic inflammation.

In addition, the previously discussed choroidal hemangiomas may have increased visualization on T2 FLAIR when compared to T1WI and T2WI, secondary to the reduced velocity of blood flow through the torturous vessels of these vascular lesions. Overall, these findings also suggest that melanin is not the primary reason behind the increased signal intensity found in T2 FLAIR imaging.

Limitations of this study include a retrospective study design and that not all tumors were imaged. From this study it is also difficult to predict the impact of objects with known electromagnetic inference, such as dental hardware, on scan interpretation.

\section{Conclusion}

The role of T2 FLAIR MRI should be further explored in patient stratification for treatment options and to potentially aid in the diagnosis of intraocular pathology. As on T1WI, uveal melanomas show increased signal intensity on T2 FLAIR sequences. Causality of the hyperintensity has not been determined, though evidence from patients with nonpigmented ocular pathologies suggests blood flow has an impact.

Similar to the brain, where lesions near the ventricles are better seen with T2 FLAIR, ocular T2 FLAIR also showed a benefit in delineating tumor margins adjacent to the vitreous humor. This increased visualization also contains the potential of identifying lesions earlier than on other MRI sequences where smaller lesions have been shown to have more favorable outcomes.

More research should be conducted to better determine the potential of T2 FLAIR in the delineation, localization, and sizing of lesions for treatment. Its potential to differentiate intraocular pathologies should also be explored. With this additional diagnostic information, T2 FLAIR would be an effective sequence to add to orbital MRI when scanning a patient with intraocular or orbital concerns. From this small collection of cases, T2 FLAIR appears to allow for better visualization of multiple lesion types than classic MRI techniques.

\section{Statement of Ethics}

This study was done with institutional review board approval and followed the international ethical standards.

\section{Disclosure Statement}

The authors have no conflicts of interest to disclose. 


\section{References}

1 Baek HJ, Lee SJ, Cho KH, Choo HJ, Lee SM, Lee YH, Suh KJ, Moon TY, Cha JG, Yi JH, Kim MH, Jung SJ, Choi JH: Subungual tumors: clinicopathologic correlation with US and MR imaging findings. Radiographics 2010;30:1621-1636.

2 Oh KJ, Kwon BJ, Han MH, Hwang PG, Kim CJ, Na DG, Chang KH: MR imaging findings of uveal leiomyoma: three cases. Am J Neuroradiol 2005;26:100-103.

3 Bakri SJ, Sculley L, Singh AD: Imaging techniques for uveal melanoma. Int Ophthalmol Clin 2006;46:1-13.

4 Gomori JM, Grossman RI, Shields JA, Augsburger JJ, Joseph PM, DeSimeone D: Choroidal melanomas: correlation of NMR spectroscopy and MR imaging. Radiology 1986;158: 443-445.

5 Mafee MF, Peyman GA, Grisolano JE, Fletcher ME, Spigos DG, Wehrli FW, Rasouli F, Capek V: Malignant uveal melanoma and simulating lesions: MR imaging evaluation. Radiology 1986;160:773-780.

6 Char DH, Kroll S, Stone RD, Harrie R, Kerman B: Ultrasonographic measurement of uveal melanoma thickness: interobserver variability. Br J Ophthalmol 1990;74:183185.

7 Mahajan A, Crum A, Johnson MH, Materin MA: Ocular neoplastic disease. Semin Ultrasound CT MR 2011;32:28-37.

8 Tailor TD, Gupta D, Dalley RW, Keene CD, Anzai Y: Orbital neoplasms in adults: clinical, radiologic, and pathologic review. Radiographics 2013;33:1739-1758.

9 Patel TR, McHugh BJ, Bi WL, Minja FJ, Knisely JP, Chiang VL: A comprehensive review of MR imaging changes following radiosurgery to 500 brain metastases. Am J Neuroradiol 2011;32:1885-1892.

10 Dewulf P, Demaerel P, Wilms G, Delanote G, Defloor E, Casselman J, Baert AL: Cerebral metastatic malignant melanoma: $\mathrm{CT}$ and $\mathrm{MR}$ findings with pathological correlation. J Belge Radiol 1993;76:318-319.

11 Escott EJ: A variety of appearances of malignant melanoma in the head: a review. Radiographics 2001;21:625-639.
12 Essig M, von Kummer R, Egelhof T, Winter $\mathrm{R}$, Sartor K: Vascular MR contrast enhancement in cerebrovascular disease. Am J Neuroradiol 1996;17:887-894.

13 Isiklar I, Leeds NE, Fuller GN, Kumar AJ: Intracranial metastatic melanoma: correlation between MR imaging characteristics and melanin content. Am J Roentgenol 1995;165: 1503-1512.

14 Uozumi A, Saegusa T, Ohsato K, Yamaura A: Computed tomography and magnetic resonance imaging of nonhemorrhagic, metastatic melanoma of the brain - case report. Neurol Med Chir (Tokyo) 1990;30:143-146.

15 Young GS: Advanced MRI of adult brain tumors. Neurol Clin 2007;25:947-973, viii.

16 Zimny A, Zinska L, Bladowska J, Neska-Matuszewska M, Sasiadek M: Intracranial lesions with high signal intensity on T1-weighted MR images - review of pathologies. Pol J Radiol 2013;78:36-46.

17 Rees JH: Diagnosis and treatment in neurooncology: an oncological perspective. $\mathrm{Br} \mathrm{J} \mathrm{Ra-}$ diol 2011;84(Spec No 2):S82-S89.

18 De Coene B, Hajnal JV, Pennock JM, Bydder GM: MRI of the brain stem using fluid attenuated inversion recovery pulse sequences. Neuroradiology 1993;35:327-331.

19 Essig M, Knopp MV, Debus J, Schonberg SO, Wenz F, Hawighorst H, van Kaick G: Fluidattenuated-inversion-recovery (FLAIR) imaging in the diagnosis of cerebral gliomas and metastases (in German). Radiologe 1999;39: 151-160.

20 Rydberg JN, Hammond CA, Grimm RC, Erickson BJ, Jack CR Jr, Huston J 3rd, Riederer SJ: Initial clinical experience in MR imaging of the brain with a fast fluid-attenuated inversion-recovery pulse sequence. Radiology 1994;193:173-180.

21 Stuckey SL, Wijedeera R: Multicentric/multifocal cerebral lesions: can fluid-attenuated inversion recovery aid the differentiation between glioma and metastases? J Med Imaging Radiat Oncol 2008;52:134-139.

22 Cheng B, Ebinger M, Kufner A, Kohrmann M, Wu O, Kang DW, Liebeskind D, Tourdias T, Singer OC, Christensen S, Warach S, Luby M, Fiebach JB, Fiehler J, Gerloff C, Thomalla G: Hyperintense vessels on acute stroke fluidattenuated inversion recovery imaging: associations with clinical and other MRI findings. Stroke 2012;43:2957-2961.
23 Liu W, Xu G, Yue X, Wang X, Ma M, Zhang R, Wang H, Zhou C, Liu X: Hyperintense vessels on FLAIR: a useful non-invasive method for assessing intracerebral collaterals. Eur J Radiol 2011;80:786-791.

24 Gawlitza M, Quaschling U, Hobohm C, Otto J, Voigt P, Hoffmann KT, Lobsien D: Hyperintense basilar artery on FLAIR MR imaging: diagnostic accuracy and clinical impact in patients with acute brain stem stroke. Am J Neuroradiol 2014;35:1520-1526.

25 Ohkawa M, Katoh T, Nakano S, Fujiwara N, Mori Y, Hino I, Tanabe M: Use of fluid-attenuated inversion recovery (FLAIR) pulse sequences for differential diagnosis of hepatic hemangiomas and hepatic cysts. Acta Med Okayama 1997;51:275-278.

26 Hjouj M, Rubinsky B: Magnetic resonance imaging characteristics of nonthermal irreversible electroporation in vegetable tissue. J Membr Biol 2010;236:137-146.

27 Malhotra A, Minja FJ, Crum A, Burrowes D Ocular anatomy and cross-sectional imaging of the eye. Semin Ultrasound CT MR 2011;32 $2-13$.

28 Mafee MF, Karimi A, Shah J, Rapoport M, Ansari SA: Anatomy and pathology of the eye role of MR imaging and CT. Neuroimaging Clin N Am 2005; 15:23-47.

29 Stroszczynski C, Hosten N, Bornfeld N, Wiegel T, Schueler A, Foerster P, Lemke AJ, Hoffmann KT, Felix R: Choroidal hemangioma: MR findings and differentiation from uveal melanoma. Am J Neuroradiol 1998;19:14411447.

30 Jagannathan J, Bourne TD, Schlesinger D, Yen CP, Shaffrey ME, Laws ER Jr, Sheehan JP: Clinical and pathological characteristics of brain metastasis resected after failed radiosurgery. Neurosurgery 2010;66:208-217.

31 Eibl-Lindner K, Furweger C, Nentwich M, Foerster P, Wowra B, Schaller U, Muacevic A: Robotic radiosurgery for the treatment of medium and large uveal melanoma. Melanoma Res 2016;26:51-57. 